\section{AB0379 EFFICACY OUTCOMES FOR ORIGINATOR TNF INHIBITORS AND BIOSIMILARS IN RHEUMATOID ARTHRITIS AND PSORIASIS TRIALS: A SYSTEMATIC LITERATURE REVIEW}

R. Moots ${ }^{1}$, C. Curiale ${ }^{2}$, D. Petersel ${ }^{2}$, C. Rolland ${ }^{3}$, H. Jones ${ }^{2}$, E. Singh ${ }^{2}$, E. Mysler ${ }^{4} .{ }^{1}$ University of Liverpool, Liverpool, United Kingdom; ${ }^{2}$ Pfizer, Collegeville, United States; ${ }^{3}$ Envision Pharma Group, London, United Kingdom; ${ }^{4}$ Organización Médica de Investigación, Buenos Aires, Argentina

Background: Regulatory approval of biosimilar versions of innovator biotherapeutics requires that new biological products be highly similar to innovator products, with no clinically meaningful differences in safety, purity, and potency. ${ }^{1,2}$ Pre-specified margins for equivalence in efficacy have been met in comparative trials of biosimilars of tumour necrosis factor inhibitors (TNFis) in rheumatoid arthritis (RA) ${ }^{3}$ and plaque psoriasis ( $\left.\mathrm{PsO}\right),{ }^{4}$ supporting biosimilarity, but differences in treatment responses between originator pivotal trials and biosimilar trials have posed some interesting questions.

Objectives: To compare American College of Rheumatology 20\% response (ACR20) and Psoriasis Area Severity Index 75\% (PASI75) responses to originator TNFis in pivotal trials with those to originator TNFis and TNFi biosimilars in biosimilar trials in $\mathrm{RA}$ and $\mathrm{PsO}$.

Methods: Historical data from originator pivotal trials (averaged across trials) were obtained from published systematic literature reviews. Searches were conducted to identify comparative randomized clinical trials of approved or proposed biosimilars of adalimumab (ADA), etanercept (ETN), and infliximab (INF) using Embase ${ }^{\circledR}$, MEDLINE $^{\circledR}$, the Cochrane Central Trials Register and Database of Systematic Reviews, and other Cochrane Library databases, and 2015/16 congress abstracts. To reduce variability, only studies conducted in disease-modifying antirheumatic drug-experienced patients treated with the same biologic dosages and assessed at the same time points were selected for analysis. Results: Of 83 publications initially identified, 16 publications were included for analysis (RA: originators, $n=4$; biosimilars, $n=6$; PsO: originators, $n=3$; biosimilars, $\mathrm{n}=3$ ). Higher proportions of ACR20 responders were found among RA patients receiving the originator biologics and biosimilars in biosimilar trials, than among patients receiving the originator biologics in pivotal trials (Table). Insufficient data were available from ADA and INF biosimilar studies in PsO; in ETN studies in $\mathrm{PsO}$, a difference was also observed in the proportions of PASI75 responders between biosimilar and pivotal trials.

Table: ACR20 and PAS175 responders in pivotal vs biosimilar trials and differences in response rates

\begin{tabular}{|c|c|c|c|c|}
\hline Product & RA trial type & $\begin{array}{l}\text { Time point } \\
\text { (wk) }\end{array}$ & $\begin{array}{c}\text { ACR20 } \\
\text { responders, \% }\end{array}$ & $\begin{array}{l}\text { Difference, pivotal vs biosim, } \\
\%\end{array}$ \\
\hline ADA & Pivotal $^{5.6}$ & 24 & 65 & - \\
\hline ADA & $\begin{array}{l}\text { Biosim } \\
\text { Biosim }^{8}\end{array}$ & $\begin{array}{l}24 \\
24\end{array}$ & $\begin{array}{l}72 \\
72\end{array}$ & $\begin{array}{c}10 \\
9\end{array}$ \\
\hline ABP 501 & Biosim 7 & 24 & 75 & 13 \\
\hline SB5 & Biosim $^{8}$ & 24 & 73 & 10 \\
\hline ETN & Pivotal $^{9}$ & 24 & 71 & - \\
\hline ETN & $\begin{array}{l}\text { Biosim } \\
\text { Biosim }^{30}\end{array}$ & $\begin{array}{l}24 \\
24 \\
\end{array}$ & $\begin{array}{l}80 \\
91\end{array}$ & $\begin{array}{l}12 \\
22\end{array}$ \\
\hline SB4 & Biosim $^{3}$ & 24 & 78 & 9 \\
\hline CHS-0214 & Biosim ${ }^{10}$ & 24 & 91 & 22 \\
\hline INF & Pivotal $^{11}$ & 30 & 50 & - \\
\hline INF & $\begin{array}{l}\text { Biosim } 12 \\
\text { Biosim }^{13}\end{array}$ & $\begin{array}{l}30 \\
30\end{array}$ & $\begin{array}{l}59 \\
59\end{array}$ & $\begin{array}{l}15 \\
15\end{array}$ \\
\hline CT-P13 & Biosim $^{12}$ & 30 & 61 & 18 \\
\hline SB2 & Biosim $^{13}$ & 30 & 56 & 10 \\
\hline Product & PsO trial type & $\begin{array}{l}\text { Time point } \\
\text { (wk) }\end{array}$ & $\begin{array}{c}\text { PASI75 } \\
\text { responders, \% }\end{array}$ & $\begin{array}{l}\text { Difference, pivotal vs } \\
\text { biosim, \% }\end{array}$ \\
\hline ETN & Pivotal $^{14,15}$ & 12 & 43 & - \\
\hline ETN & Biosim 4 & 12 & 72 & 40 \\
\hline GP2015 & Biosim 4 & 12 & 70 & 39 \\
\hline
\end{tabular}

Conclusions: Differences were observed in treatment response rates between originator pivotal trials and more recent trials of originator biologics and their respective biosimilars. Such differences in outcomes may be attributable to fundamental differences in study design and/or baseline patient characteristics, which require further analysis. Additional research is also needed to explore the clinical relevance of these differences.

\section{References:}

[1] US Food and Drug Administration. http://www.fda.gov/downloads/Drugs/ GuidanceComplianceRegulatorylnformation/ Guidances/UCM291128.pdf.

[2] European Medicines Agency. http://www.ema.europa.eu/docs/en_GB/document library/Scientific guideline/2015/01/WC500180219.pdf.

[3] Emery P, et al. Ann Rheum Dis. 2017;76:51-7.

[4] Griffiths CE. Br J Dermatol. 2016. Oct 27 [e-pub].

Disclosure of Interest: R. Moots Grant/research support from: Novartis, Pfizer, Consultant for: Abbvie, BMS, Cellgene, Chugai, C. Curiale Shareholder of: Pfizer, Employee of: Pfizer, D. Petersel Shareholder of: Pfizer, Employee of: Pfizer, C. Rolland Employee of: Envision Pharma Group, H. Jones Shareholder of: Pfizer, Employee of: Pfizer, E. Singh Shareholder of: Pfizer, Employee of: Pfizer, E. Mysler Consultant for: Abbvie, BMS, Pfizer, Roche, Pharma, GEMMA, Mabxience DOI: 10.1136/annrheumdis-2017-eular.1851

\section{AB0380 RESULTS FROM A RANDOMIZED, SINGLE-BLIND, SINGLE-DOSE, PARALLEL-GROUP STUDY IN HEALTHY SUBJECTS DEMONSTRATING PHARMACOKINETIC SIMILARITY BETWEEN ABP 710 AND INFLIXIMAB}

E. Krishnan, V. Chow, N. Zhang, A. Kaliyaperumal, P. Kaur. Amgen, Thousand Oaks, United States

Background: ABP 710 is being developed as a biosimilar with the same amino acid sequence as infliximab, an anti-tumor necrosis factor therapy. Analytical and functional comparisons between ABP 710 and infliximab have been conducted and completed.

Objectives: This report describes the results of analyses comparing the pharmacokinetics (PK), safety, and immunogenicity of ABP 710 and infliximab sourced from the European Union (EU)

Methods: This was a single-blind, single-dose, parallel-group study among healthy adults, 18 to 45 years of age and with a body mass index of 18 to $30 \mathrm{~kg} / \mathrm{m}^{2}$. Subjects were randomized to receive a $5 \mathrm{mg} / \mathrm{kg}$ intravenous infusion of either ABP 710 or infliximab. The primary objective of this analysis was demonstration of PK similarity of ABP 710 to infliximab based on area under the serum concentration-time curve from time 0 extrapolated to infinity $\left(A \cup C_{i n f}\right.$; primary endpoint). PK equivalence was deemed achieved if the geometric mean (GM) ratio and its $90 \%$ confidence interval $(\mathrm{Cl})$ for $A U C_{\text {inf }}$ was within the range of 0.80 and 1.25. Secondary endpoints included maximum observed serum concentration $\left(\mathrm{C}_{\max }\right)$, area under the serum concentration-time curve from time 0 to last quantifiable concentration $\left(A \cup C_{\text {last }}\right)$, safety, and immunogenicity.

Results: Pharmacokinetics: A total of 49 subjects received ABP 710 and 49 subjects received infliximab. Following a single dose, the adjusted least square (LS) $\mathrm{GM}$ of $A \cup C_{\text {inf }}, A \cup C_{\text {last }}$, and $C_{\text {max }}$ for $A B P 710$ was $33559 \mu \mathrm{g} \cdot \mathrm{h} / \mathrm{mL}, 31789$ $\mu \mathrm{g} \cdot \mathrm{h} / \mathrm{mL}$, and $123 \mu \mathrm{g} / \mathrm{mL}$, respectively. The adjusted LS GM of $A U C_{\text {inf }}, A \cup C_{\text {last }}$, and $\mathrm{C}_{\max }$ for infliximab was $33706 \mu \mathrm{g} \cdot \mathrm{h} / \mathrm{mL}, 31847 \mu \mathrm{g} \cdot \mathrm{h} / \mathrm{mL}$, and121 $\mu \mathrm{g} / \mathrm{mL}$, respectively. Ratios of adjusted LS GMs $(90 \% \mathrm{Cls})$ between ABP 710 and infliximab for $A \cup C_{\text {inf }}, \mathrm{AUC}_{\text {last }}$, and $\mathrm{C}_{\max }$ were 0.996 (0.904, 1.096), 0.998 (0.918, $1.086)$, and $1.021(0.962,1.083)$, respectively.

Safety: There was one subject in the infliximab group who developed polyarthritis that resolved with treatment and the subject completed the study. There were no deaths, other serious adverse events, or treatment-emergent adverse events (TEAEs) leading to discontinuation from the study. The incidence of TEAEs was similar in the two treatment groups (ABP 710: 83.7\%; infliximab: 83.7\%); the majority of TEAEs were mild or moderate. The most frequently reported TEAEs were somnolence, headache, nasopharyngitis, upper respiratory tract infection, nausea, and lethargy.

Immunogenicity: All subjects tested negative for antidrug antibodies (ADAs) prior to dosing. At the end of study (Day 57), $40 \%$ of subjects in the ABP 710 group and $27 \%$ in the infliximab group were positive for binding ADAs, and $13 \%$ of subjects in the ABP 710 group and $19 \%$ in the infliximab group were positive for neutralizing ADAs.

Conclusions: Results of this phase 1 study demonstrate PK similarity between ABP 710 and infliximab sourced from the EU among healthy subjects. The safety and immunogenicity profile were comparable between the treatment groups.

Disclosure of Interest: E. Krishnan Shareholder of: Amgen Inc., Employee of: Amgen Inc., V. Chow Shareholder of: Amgen Inc., Employee of: Amgen Inc., N. Zhang Shareholder of: Amgen Inc., Employee of: Amgen Inc., A. Kaliyaperumal Shareholder of: Amgen Inc., Employee of: Amgen Inc., P. Kaur Shareholder of: Amgen Inc., Employee of: Amgen Inc.

DOI: 10.1136/annrheumdis-2017-eular.3281

\section{AB0381 CHANGE IS GOOD, BUT WHAT IS BETTER? RETROSPECTIVE STUDY IN CLINICAL PRACTICE FIRST SWITCH WITH DIFFERENT BIOLOGICAL THERAPIES IN RHEUMATOID ARTHRITIS}

F.A. Oieda, C. Pérez-García, E. Beltran, A. Pros, T. Salman-Monte, F. Castro, L. Polino, P. Corzo, I. Carrión, S. Castell, P. Benito. Rheumatology, Hospital del Mar, Barcelona, Spain

Background: The effectiveness of the switch when the first anti-TNF failure in patients with rheumatoid arthritis has been demonstrated in multiple studies. But what is more effective, if you make the switch to another anti-TNF or another molecule, is not clearly defined.

Objectives: A retrospective study was performed in clinical practice to determine if there is a response to DAS 28 at 6 months of change and whether there is a difference in response if the switch is performed on another anti-TNF or another biological.

Methods: From a total of 254 that met ACR 2010 criteria for RA, which have been biologically treated at Rheumatology of the Parc Salut Mar from 2000 to 2016, $61(24 \%)$ were the first switch and the DAS 28 response at 3 and 6 months of follow-up. The following variables were analyzed: age, sex, years of evolution RA, erosions, FR, ACPA, type of biological treatment, DAS 28 at the start of the switch, 3 months and 6 months, $\%$ of patients presenting DAS $28<2,6$ at 6 months. The statistical study was performed with SPSS 20 for paired and independent quantitative variables with Student's $T$ and chi2 for qualitative variables Results: Of the total of 61 first treatment changes, 27 (44.3\%) were to another anti-TNF alpha, $23(37.7)$ to tocilizumab (TCZ), 7 to abatacept $(11.5 \%)$ and 4 
to RTX $(6,6)$. The demographic and response data DAS 28 are shown in Table 1. There are no differences in the years of evolution, $\%$ of women, FR or ACPA positive, erosions and disease activity, as measured by DAS 28 , before the switch, between The two groups (anti-TNF vs non-anti-TNF). Patients in the anti-TNF group were slightly younger than non-anti-TNF.When the DAS 28 response is evaluated at 3 and 6 months, modifying the treatment is effective (DAS 28 beginning 4,40 vs DAS 286 months $2.8 p<0.001$ ). When assessing the response to change, there is no difference in the DAS 28 response at 3 months or 6 months, if you switched to anti-TNF or non-anti-TNF ( 3.18 vs $2.52 \mathrm{p}=0.122$ ).

When comparing the patients with anti TNF alpha vs TCZ, $62.5 \%$ of the patients with TCZ are in remission compared to $38,5 \%(p=0.047)$.

Table 1

\begin{tabular}{lcccc}
\hline & $\begin{array}{c}\text { Total } \\
\mathrm{n}=61\end{array}$ & $\begin{array}{c}\text { Swich anti-TNF alpha } \\
\mathrm{n}=26\end{array}$ & $\begin{array}{c}\text { Swich No anti-TNF alpha } \\
\mathrm{n}=35\end{array}$ & $\mathrm{p}$ \\
\hline Age (years) & $60.08 \pm 11,5$ & $56.19 \pm 8,4$ & $62.97 \pm 12,8$ & 0.023 \\
Sex (\% M) & 80.3 & 84.6 & 77.1 & 0.532 \\
Years evolution (years) & $17.44 \pm 9,4$ & $18.92 \pm 11,6$ & $16.34 \pm 7,4$ & 0.298 \\
Erosion (\%) & 90.2 & 92.3 & 88.6 & 1.000 \\
FR+ (\%) & 77.0 & 76.9 & 77.1 & 1.000 \\
ACPA+ $(\%)$ & 91.8 & 88.5 & 94.3 & 0.642 \\
\hline
\end{tabular}

Table 2

\begin{tabular}{lcccc}
\hline & $\begin{array}{c}\text { Total } \\
\mathrm{n}=61\end{array}$ & $\begin{array}{c}\text { Swich anti-TNF alpha } \\
\mathrm{n}=26\end{array}$ & $\begin{array}{c}\text { Swich No anti-TNF alpha } \\
\mathrm{n}=35\end{array}$ & $\mathrm{p}$ \\
\hline DAS 28 Swich & $4.40 \pm 1,38$ & $4.61 \pm 1,5$ & $4.21 \pm 1,3$ & 0.216 \\
DAS 28 3 months & $3.18 \pm 1,52$ & $3.52 \pm 1,09$ & $2.96 \pm 1,7$ & 0.167 \\
DAS 28 6 months & $2.8 \pm 1,54$ & $3.18 \pm 1,74$ & $2.52 \pm 1,3$ & 0.122 \\
DAS 28 <2.6 6 m (\%) & 52.5 & 38.5 & 62.5 & 0.047 \\
\hline
\end{tabular}

Conclusions: In this retrospective study in daily clinical practice, it is evident that the change in treatment after failure of the first biological one, without differences if the change is to an anti TNF or another treatment. The percentage of patients who are remission at 6 months is higher if the change is at TCZ. Given the small number of patients, larger studies would be needed to confirm the results. References:

[1] Johnston SS et col. Comparison of Biologic Disease-Modifying Antirheumatic Drug Therapy Persistence Between Biologics Among Rheumatoid Arthritis Patients Switching from Another Biologic. Rheumatol Ther.

Disclosure of Interest: None declared

DOI: 10.1136/annrheumdis-2017-eular.3375

\section{AB0382 OUTCOMES OF ETANERCEPT THERAPY IN ELDERLY RHEUMATOID ARTHRITIS PATIENTS: AN INVESTIGATION OF THE AKITA ORTHOPEDIC GROUP ON RHEUMATOID ARTHRITIS REGISTRY}

${ }_{\text {H. Aonuma }}{ }^{1}$, T. Kashiwagura ${ }^{2}$, M. Urayama ${ }^{3}$, M. Kobayashi $^{4}$, T. Aizawa $^{5}$ Y. Sugimura ${ }^{6}$, N. Miyakoshi ${ }^{7}$, Y. Shimada ${ }^{7} .{ }^{1}$ Orthopedic Surgery, Kakunodate Municipal Hospital, Senboku; ${ }^{2}$ Orthopedic Surgery, Akita City Hospital, Akita; ${ }^{3}$ Orthopedic Surgery, Ogachi Central Hospital, Yuzawa; ${ }^{4}$ Orthopedic Surgery, Hiraka General Hospital, Yokote; ${ }^{5}$ Orthopedic Surgery, Kita Akita Municipal Hospital, Kita Akita; ${ }^{6}$ Orthopedic Surgery, Nakadori General Hospital; ${ }^{7}$ Orthopedic Surgery, Akita University Graduate School of Medicine, Akita, Japan

Background: The Akita Orthopedic Group on Rheumatoid Arthritis (AORA) encompasses 32 physicians and 28 clinics providing medical care to rheumatoid arthritis (RA) patients in Akita Prefecture, Japan. The patient registry for this group (the AORA registry) reflects actual clinical data on RA therapy in Akita, where the proportion of elderly (age $\geq 65$ years) residents in the population is the highest in Japan. Etanercept (ETN) is a tumor necrosis factor inhibitor reportedly associated with fewer adverse event-related treatment discontinuations than other drugs of this class. However, few evaluations of the efficacy and safety of ETN have been reported for elderly populations.

Objectives: Based on data from the AORA registry, we aimed to investigate the continuation rate for ETN therapy, reasons for discontinuation, and therapeutic effects among elderly RA patients living in Akita.

Methods: Among 204 AORA-registered patients starting ETN therapy between January 2009 and August 2014, data for the 73 patients (35.8\%) who were $\geq 65$ years old at the initiation of therapy were evaluated. Mean age was $72.4 \pm 4.7$ years (range $65-83$ years), and $79.5 \%$ were women. Mean disease duration was $15.1 \pm 12.6$ years (range 9 months- 55 years), $13.7 \%$ of patients were switching from another biologic agent, $49.3 \%$ could perform activities of daily living (ADL) independently, and $65.8 \%$ had at least one of the following comorbidities: hypertension, diabetes, respiratory disorder, cardiovascular disease, and cerebrovascular disease. We evaluated the 1-year cumulative continuation rate for ETN therapy using the Kaplan-Meier method, and investigated the characteristics of patients who discontinued treatment because of adverse events (AE cohort) or lack of efficacy (LOE cohort). We evaluated efficacy in 55 patients for whom Disease Activity Score - C-reactive protein assessments were possible, based on European League Against Rheumatism (EULAR) criteria.

Results: The 1-year cumulative continuation rate for ETN therapy was $87.2 \%$, and 24 patients discontinued treatment. The AE and LOE cohorts contained 12 and 7 patients, respectively. The AE cohort had a mean age of 75.5 years at the start of treatment, with a mean disease duration of 20.7 years, $8.3 \%$ of patients switching from another biologic agent, $16.7 \%$ performing ADL independently, and a comorbidity rate of $100 \%$. Corresponding values for the LOE cohort were: mean age, 71.4 years; disease duration, 12.7 years; switching from another biologic agent, 42.9\%; performing ADL independently, $57.1 \%$; and comorbidity rate, $28.6 \%$. Efficacy was noted for $81.8 \%$ of all patients with 52 weeks of ETN therapy, achieving good efficacy in 21 cases and moderate efficacy in 24 cases. Conclusions: Retention rate and efficacy were considered satisfactory in elderly RA patients receiving ETN therapy. The risk of adverse events was suggested to increase with increasing age, declining ADL, and presence of comorbidities. These factors require attention when prescribing ETN therapy.

\section{References:}

[1] Cho SK, Sung YK, Kim D, et al. Drug retention and safety of TNF inhibitors in elderly patients with rheumatoid arthritis. BMC Musculoskelet Disord. 2016; 17: 333 .

Disclosure of Interest: None declared

DOI: 10.1136/annrheumdis-2017-eular.6102

\section{AB0383 SUBCLINICAL BRAIN DAMAGE IN PATIENTS WITH RHEUMATOID ARTHRITIS AND ITS RELATIONSHIP TO TNF BLOCKER THERAPY}

S. Sağ, I. Tekeoğlu, M.S. Sağ, A. Kamanlı, K. Nas. Department of Physical Medicine and Rehabilitation, Rheumatology, Faculty of Medicine, Sakarya University, Sakarya, Turkey, sakarya, Turkey

Background: RA is a chronic disease with a yet unclarified etiology, which causes the activation of pro-inflammatory pathways that bring about joint and systemic inflammations (1).In recent years, the pathophysiology of brain damage that can occur in RA has drawn attention. Emphasis is being put on the possibility that brain damage occurs due to blood-brain barrier (BBB) damage that is linked to chronic inflammation

Objectives: In this study, we aimed to investigate the peripheral blood levels of brain-specific proteins such as $\mathbf{S} 100$ beta and GFAP (glial fibrillary acidic protein), the differences in these proteins in patients who did and did not undergo TNF blocker therapy and their relationship with cranial MR lesions, disease activity and cognitive functions with the purpose of determining CNS (central nervous system) damage in patients with rheumatoid arthritis (RA).

Methods: 58 RA patients $(47(81.0 \%)$ females, $11(19.0 \%)$ males) and 34 healthy controls $(24(70.6 \%)$ females, $10(29.4 \%)$ males) were included in the study. All RA patients were on synthetic DMARD therapy at the beginning. While 30 patients continued SDMARD therapy, 28 patients with high disease activity were started on TNF blocker therapy. All demographic characteristics of the patients were recorded. Disease activity was evaluated using DAS28. The Mini-Mental State Examination (MMSE) was used to evaluate cognitive functions, and the Fazekas Scale was used to assess the cranial MRI lesions. The peripheral blood S100 beta, GFAP, claudin, IL-17, IL-1 beta levels of the patients were measured at the beginning and on the 6th month.

Results: Demographic characteristics were similar between the two groups and no statistical difference was detected between the patient group and the control group in terms of sex, age, and BMI. ( $p>0.05)$ S100 beta and GFAP levels were higher to a significant degree compared to the control group. $(p<0.05)$ In the group that was started on TNF blocker therapy, S100 beta and GFAP levels were detected to have decreased significantly 6 months after treatment compared to the start of treatment. $(p<0.05)$ No difference was found between the RA and control groups in terms of hyperintense lesions seen in the cranial MRI. $(p>0.05)$ As the lesions in the deep white matter seen in the cranial MRI of RA patients increased, their $S 100$ beta levels were also seen to increase. $(p<0.05)$

Conclusions: In conclusion, next to decreasing disease activity and joint erosions by suppressing inflammation, anti-TNF therapy in RA can also suppress potential brain damage linked to subclinical BBB (blood-brain-barrier) dysfunction. Further studies with broader participation and longer patient follow-up are needed to reinforce this hypothesis.

References:

[1] McInnes, I.B. and Schett, G. (2011). Thepathogenesis of rheumatoidarthritis. N Engl J Med 365, 2205 2219.doi:10.1056/ NEJMra1004965.

Disclosure of Interest: None declared

DOI: 10.1136/annrheumdis-2017-eular.2315

\section{AB0384 CLINICAL AND RADIOLOGICAL EVOLUTION IN RHEUMATOID ARTHRITIS (RA) PATIENTS AFTER DEINTESIFICATE BIOLOGICS}

J. Uceda, R. Hernandez, J.L. Marenco. Rheumatology, Valme University Hospital, Seville, Spain

Background: RA is the most common chronic inflammatory arthritis. About $30 \%$ of patients are treated with biological therapy (BT). Deintensification of BT for patients in clinical remission, is a strategy used in clinical practice to reduce side effects and burden.

Objectives: The primary endpoint was evaluate clinical and radiological behavior of the RA in patients receiving BT at reduced doses. 